\title{
Impact of Technological Innovation Management on Health Care Service Delivery: A Systematic Review
}

\author{
Ebenezer Larnyo \\ Department of Health Policy and Management, Jiangsu University, School of Management, \\ 301 Xuefu Road, Zhenjiang, Jiangsu Province, China \\ Baozhen Dai* \\ Department of Health Policy and Management, Jiangsu University, School of Management, \\ 301 Xuefu Road, Zhenjiang, Jiangsu Province, China \\ Abigail Kusiator \\ University of Ghana, Legon, Ghana \\ Ebenezer Ababio Tetteh \\ School of Management, Jiangsu University, 301 Xuefu Road, Zhenjiang, Jiangsu Province, China
}

This work was funded by the National Nature Science Foundation of China (71774069).

\section{Abstract}

The objective of this study is to provide a comprehensive, systematic review on the progress of research on technological innovation management literature in healthcare delivery and its impact, whereby we seek to highlight the knowledge gaps, and provide researchers and scholars' approaches for future research. We statistically reviewed and analyzed 289 articles relevant to our research objectives using publications in journals, articles, conferences and those available in press from 1990 to 2018. Based on which we critically synthesized 36 articles for content analysis (conceptual, and empirical studies) and created a framework for technological innovation management research. Content analysis showed some appreciable contributions of conceptual, empirical, evidential and review articles in the field. We observed that though there has been some research into the area of innovation, open innovation and the application of technological innovation in the area of health care delivery, little study has been done in assessing the impact management of such technological innovation on the delivery of public health care services to citizens; thus the use of our proposed framework will provide guidance for researchers and scholars seeking to advance discussions and studies in this area.

Keywords: Technological innovation management, technological innovation, process innovation, open innovation, public health, research and development (R \& D).

\section{Introduction}

Governments all over the world are plagued with the issue of improving public sector performance and at the same time, besieged with containing expenditure growth Curristine (2005b). While factors such as ageing population, increasing healthcare and pension costs add to budgetary pressures on governments' finances, citizens are constantly demanding for better accountability for the use of their taxes. The problem however is that, governments have been hesitant in supporting innovation drives, or at best initiate the process of innovation in fields that are their direct responsibility. This may partially be due to the government's lack of appreciation of the positive impact technological innovation has on the performance of the economy at the level of private sector firms Evangelista and Vezzani (2010) and the entire country's economic performances Sapprasert and yvarde Clausen (2012). This may also be due to the fact that the fundamental differences that exist between public and private sectors have not been properly considered in previous attempts to mea- sure the impact of innovation in the public sector. According to Maghsoudi et al. (2015), some of these fundamental differences could be budget constraints, organizational objectives and conditions such as decision-making, or incentive strategies. While in the private sector, profit plays a critical role; in the public sector the main concern would be providing better service to society, such as enhancing peoples' well-being DIISR (2011).

Though there is no blueprint for enhancing public sector efficiency, diverse approaches to reforming key institutional arrangements have been adopted. These reforms include increasing devolution and decentralization, strengthening competitiveness, transforming workforce structure, size, and HRM arrangements; changing budget practices and procedures; and introducing result-oriented approaches to budgeting and management Curristine (2005a). The evidence of the role technology plays in the success of an organization or firm is extremely significant. Technology has now become the tool to create competitive advantage by introducing novel products or technological processes that attract new customers, creating barrier that can deter entry of rivals, or changing the rules of competition in their respective industries where they operate Golder and Tellis (1993); Zahra et al. (1995). This suggests that the competitiveness of an organization is dependent on how it prudently uses and 
manages its technologies and technological assets. For a firm to remain relevant in this ever changing world, there is the need to innovate and invest in new technologies and ideas. However, it is important to recognize that successful technological innovations cannot be managed in the same way ordinary businesses are managed with the use of traditional management controls Kurhekar and Ghoshal (2010).

The primary objectives of this review are to systematically review and assess the current status, by providing a comprehensive review of the progress of technological innovation management research in healthcare delivery, and also seek to highlight the knowledge gaps and provide researchers and scholars' approaches for future research. We explore the patterns of journal publications, contents by characteristics, outcomes, antecedents, theories, and methods used. Based on these patterns, critical analysis of extant research is performed, and a framework for future research directions with respect to content, theory and methodology provided. There are however substantial knowledge gaps in content, theory, and methodology due to the fragmented nature of the literature.

\section{Methodology}

Our literature search returned 1977 research publications in journals, articles, conferences and those available in press from 1990 to 2018 in the following 22 journals: International journal of medical informatics, health affairs, health affairs project hope, health care management review, BMC medical informatics and decision making, journal of medical systems, studies in health technology and informatics, BMC health services research, journal of general internal medicine, journal of medical internet research, journal of the American medical informatics association, journal of the American medical informatics association (JAMIA), population health management, technological forecasting and social change, telemedicine and E-health, American journal of managed care, journal of advanced nursing, nursing economics, progress in cardiovascular diseases, telemedicine journal and Ehealth, the American journal of managed care. Of these, 289 full-text papers were assessed based on our inclusion criteria, after which we critically synthesis 36 articles for content analysis (conceptual, quantitative and empirical studies).

We relied on Web of Science database as our main source of articles for a systematic review process proposed by Tranfield et al. (2003); Moher (2009). We also conducted search in Emerald Insight, ScienceDirect, and Engineering Village databases using the following keywords: innovation, healthcare, technology, research and development (R\&D), open innovation, service delivery, technological, management, invention, process innovation, diffusion, technological innovation, and innovation management as shown in the flow diagram in Figure 1. The reason for relying on web of science though we performed searches in other databases is that, we realized most of the articles in those other databases have had an overlap with those in the web of science. It is worth noting that we also searched in Google scholar website for articles. This is because, Google scholar gives a comprehensive citation counts and has been used for reviews widely in recent years Harzing and Wal (2008). However, for those articles to be considered, they must be articles in which contributions to the topic of this review are significant.

We queried the databases to extract the articles for instance in web of science, by using advanced search where we were able to combine field tags, Boolean operators, parentheses, and query sets to create our query. The review used only articles written and published in English. The inclusion criteria we used to consider articles as part of this review is; it must either have technological innovation management or any of our keywords in its keywords list or in its abstract.

This review analyzes the content by extracting findings from several published articles and review papers; the findings were then compared and synthesized. 


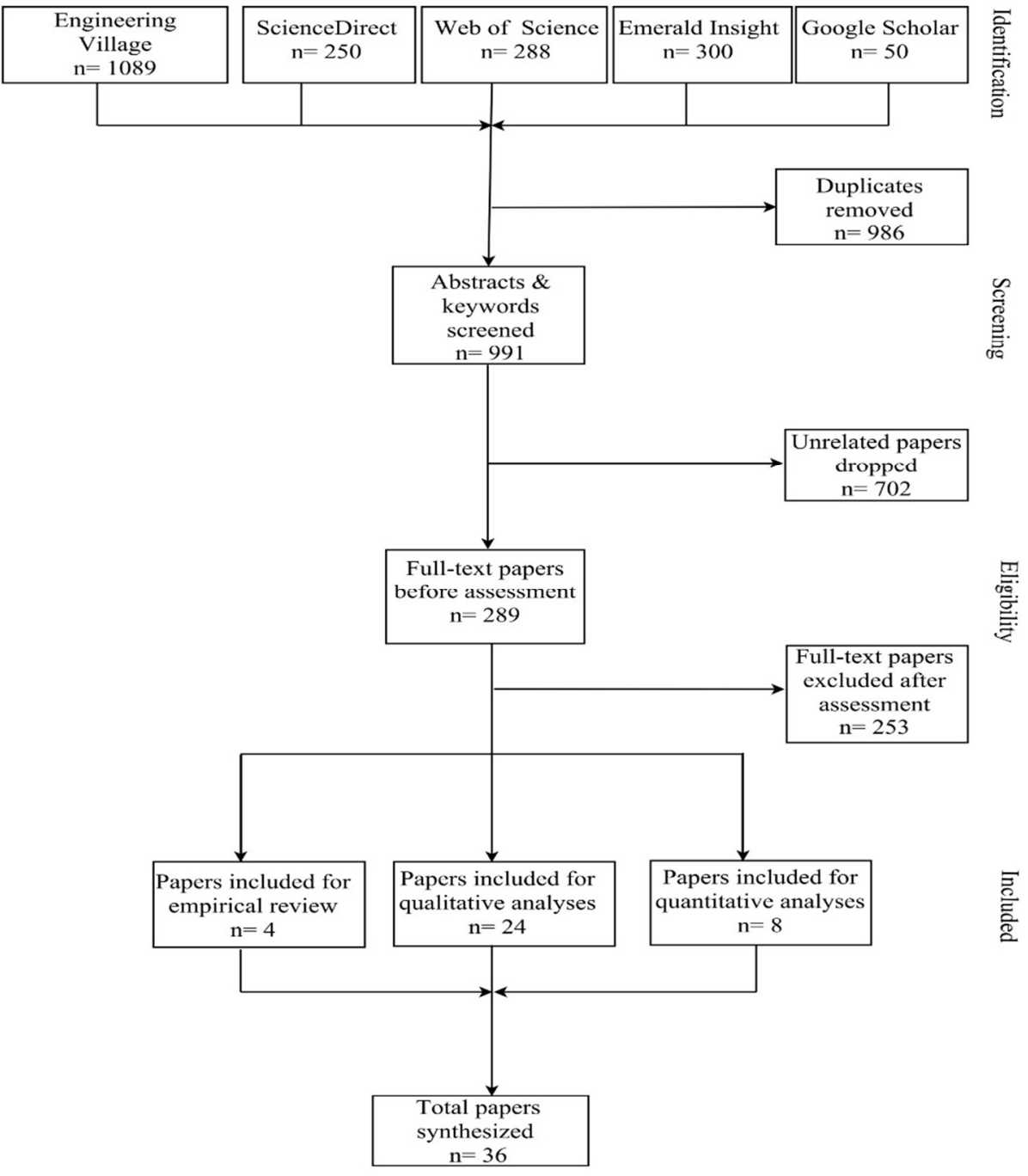

Figure 1. Flow diagram of systematic review steps

\subsection{Analyses of content of selected articles on technological innovation management \\ 2.1.1 Conceptual Studies}

In the quest of an organization to expand and meet the expectation of stakeholders and customers for performance Gyampoh-Vidogah et al. (2009), there is sometimes a tendency to rely completely on technology as an intellectual capital to lead such expansions. However, the absence of management of such technologies or knowledge, makes it difficult for hiring and training of employees who are competent enough to meet such demands. Few researchers have attempted to link the issues of innovation and management. One of such is Giannopoulou et al. (2010) who researched into the academic and the managerial perspectives of open innovation based on a literature review of 134 articles. In their review, they categorized open innovation literature in the academic perspective as concept development, organizational design and the boundaries of the firm, open strategy, the factors that influence open innovation such as culture and leadership, communities for distributing co-creation among customers and other collaborating actors, intellectual property issues such as patenting and appropriation, innovation intermediaries and the triple helix: industry, academia and government policy Hossain et al. (2016), while in the managerial perspective, they categorized open innovation as an "open" strategy and the organization, leveraging leadership to motivate employees and bringing in cultural change, creating value from external relationships such as alliances, communities, intermediaries and academia and management of intellectual property.

A study by da Mota Pedrosa et al. (2013) claimed that the transformation and exploitation of external knowledge are associated with a distinct set of managerial characteristics. Alexy and George (2013) also conducted a research to establish the relationship between open innovation model and firm value. Their research findings showed that engaging in open innovation practices positively affects a firm's market value. According 
to Christiansen et al. (2013), managers in the effort of accepting open innovation, need to consider it at both company and project levels. According to them, it is not enough to have guidelines for open innovation only on a project level. The concepts of technological innovation management consider first of all the firm's understanding of what technological innovation management is; what it is not, and the kind of innovation that is suitable. Zhou et al. (2005) outlined two types of breakthrough innovations. Tech-innovation which is based on the extent of technological advancement; and involves introduction of radically new technological knowledge, high-quality technical innovations, and new advanced technologies which are aimed at replacing inferior ones, any or all of which according to Zhou et al. (2005); Ulaga and Eggert (2006); Zeithaml (1988) help to increase value. The second type of breakthrough innovation is market-innovation which is a departure from the existing market segment aimed at serving new customers in new markets Benner and Tushman (2003). This departure from existing segments and customers explains why the product requires a major learning effort on behalf of buyers in the challenge to understand or evaluate the product's full benefits Zhou et al. (2005). Technological innovation management does not take place in only the internal environment, but also in the external environment. Some pure technological management items are licensing, acquisition, technological status, R\&D and technological policies. Strategy and organizational structure are important aspects of an organization's internal environment, and they have an impact on innovation management practices Duin et al. (2007). Chesbrough (2003), one of the pillars in championing the agenda of open innovation, argues that in order to create value in any firm there is the need to embrace such external ideas and knowledge to augment the internal R \& D.

While other works have focused on either the management of the external ideas or internal ideas, Kurhekar and Ghoshal (2010) proposed a step-by-step process to conceptualize technological innovation management which seems to integrate the general traditional management roles with technology management. In their paper, they outlined the various phases a new idea will have to pass through from its conception to its commercialization for it to yield its intended benefit. Their process commences with an identification of the opportunities that exists for the business, then to the identification of the innovation, the assessment and strategy phase, the product promotion/ innovation delivery phase, the benefit realization phase then finally the innovation sustainability phase. According to Kurhekar and Ghoshal (2010), the business opportunity which forms the core of the first phase of the technological innovation management process is the reason for which the innovation should be undertaken. They stressed that, until the opportunities available to the business are identified, innovation cannot be identified. At the business opportunity phase, a management committee is formed to oversee the practices of TIM by identifying the core business team that will take charge of looking for the various opportunities that are available to the business Kurhekar and Ghoshal (2010) and also identify the potential business capabilities and need for innovation, while performing benefit assessment.

The second phase is the identification of innovation Kurhekar and Ghoshal (2010), where high level innovative ideas are identified and documented. A taskforce is then formed consisting of personnel from the various key areas of the firm or organization who will be in charge of presenting the business opportunities to the task force, who then identify the necessary approach to use to determine the innovation means or product to satisfy the business opportunities. These approaches are used to obtain a consensus on the innovation idea that should be used to satisfy the various business opportunities identified. After which the ideas captured are presented to the management committee. These ideas are approved by the management committee are pushed to the next phase of the TIM methodology. According to Kurhekar and Ghoshal (2010), the innovation assessment and strategy phase is very critical to the innovation process of a firm. The various innovative ideas solicited are reviewed, and a joint application design (JAD) Haag et al. (1998); Jennerich (1990) and discovery sessions are conducted in order to expand the innovation idea and also perform must haves, should haves, could haves, won't haves ratings to prioritize Clegg and Barker (1994) the innovation items. This phase includes performing enterprise architecture review and impact analysis where prototypes are developed and built, simulations are created and feedbacks are sought from the stakeholders Kurhekar and Ghoshal (2010). The ideas that survive the innovation assessment and strategy and testing process are further developed and altered until they are ready to be executed as a part of the business offerings. This phase is executed in parallel with the product promotion and commercialization phase where there is planning for how to manage the program amongst other essential activities. However, they were quick to note that, this phase is mostly unique to firms and, unless the new product causes it to have to drastically alter the typical way that its go-to-market strategy Friedman (2002); Zoltners et al. (2004) functions, then this part of the innovation management process would be relatively commonplace in the firm. The next phase of the TIM, is the benefit realization Ward and Elvin (1999) phase where the benefits realized are validated against the ones outlined at the business opportunity identification phase. This phase consists of a pilot roll-out of innovative product to the pilot customers and the full migration step where all the risks and uncertainties are looked at on high priority and resolved with quick turnaround time. This step takes cognizance of the lessons learnt from the execution and these lessons are captured and documented which then becomes the document for reference in terms of best practices in the life of the innovation process. Though there are great potentials when technological innovations are commercialized and 
operationalized, it may be challenging for such new technologies to succeed alone in the market Chesbrough (2010). In order for innovation to be sustainable, there is the need for the adoption of suitable business models to support the potentials of new technologies and technological innovations, and those models need to be adopted to improve sustainability on different levels Rantala et al. (2018).

Long et al. (2016) have also taken cognizance of this argument and has added that the adoption of technological innovation alone may not achieve optimal outcomes due to mismatches between the design of technological innovation and the context within which they are ultimately used. Little (2005) 's argument that, innovation is considered to be sustainability-driven if the creation of new products and services, new market space, or processes are driven by social, environmental or sustainability issues further supported the sustainability idea. Based on these sound arguments, we wish to state that in order for the innovative product or process to stand the test of time, there is the need to integrate sustainability considerations (social, environmental, financial) into a firm's system from the idea generation phase to research and development (R \& D) and commercialization. These considerations apply to products, services and technologies, as well as new business and how organizations are modeled Charter and Clark (2007).

Greenhalgh et al. (2004) addressed the issues of how innovation can be spread or diffused and sustained in health service delivery and organization by considering both defining and measuring the diffusion of innovation in organizations through their systematic and reproducible literature review which gave rise to content and process.

\subsection{Impact of technological innovation on healthcare delivery \\ 2.2.1 Conceptual Studies}

There are several evidences of literature of how the incorporation of technological innovation has impacted positively on the delivery of health care services to customers. Langer et al. (2013) argued that technology could be exploited to improve patient care process by integrating automatic identification and data capture (AIDC) and mobile \& wireless $(\mathrm{M} \& \mathrm{~W})$ technologies. In their paper, they did an extensive analysis of processes related to the operating theatre, which pose a good example of a composite and complex environment where clinical activities need to be concerted with a number of preparatory activities. They then designed, developed and implemented a set of organizational models, acknowledged procedures and ICT tools to improve actual support, safety, reliability and traceability within the management process of surgical kits and instruments in the operating room. Li et al. (2012) 's cross-sectional qualitative study in the Emergency Departments (EDs) of two large Australian metropolitan public teaching hospitals through a semi-structured, in-depth interviews with five nurse practitioners, four senior physicians and five senior nurses shows how Nurse Practitioners (NP) incorporated the use of ICT as a mechanism to support their new clinical role within Emergency Departments. After an analysis using a grounded theory approach on the transcribed interviews, they developed themes in relation to the conceptualization of the ED nurse practitioner role and the influences of ICT upon the role. Li et al. (2012) observed that ICT supported the advanced practice dimension of the NP role in two ways: by enhancing the timeliness and quality of diagnostic due to the availability and completeness of electronic patient information, and also expediting patient access to appropriate care through therapeutic decision-making. They were quick to add that though ubiquity of patient data sourced from a central database supported and improved quality of communication between health professionals within and across sites, with wider diffusion of the EMR holds the potential to further facilitate team-based, holistic care, there is the need to make sure that the integration of ICT into work practices without detracting from provider-patient interaction is crucial to ensure utilization of such interventions and realization of potential benefits. Gold (2013) explored the real-world connection between health information technology (HIT) and the transformation of care delivery. The study discovered that the functionalities supported by HIT are integral to creating the information flow required for innovations such as medical homes, accountable care organizations and bundled payment. As it is normal with any form of innovation, technological innovation also brings with it some level of uncertainty due to the change in existing business workflow and processes. The healthcare sector is not spared from those level of uncertainty as there is also a confusion between pursuing the competitive advantage of cutting edge technology and the risk of uncertainty associated with it Kurhekar and Ghoshal (2010) .

There is a need to have a trade-off between bringing in sufficient level of technological innovations to provide quality services at lesser cost and managing the risks and uncertainties it leads to. It is very rare to find a single organization, undertaking technological innovations in a vacuum of an industrial environment. This may be due to the fact that complementary innovations are usually required before a particular technology is suitable for commercial application. According to Adler-Milstein et al. (2014), data from the Information Technology Supplement to the American Hospital Association's 2012 annual survey of acute care hospitals suggests that 42 percent of US hospitals have telehealth capabilities. However, this leverage is only available to hospitals like teaching hospitals which are equipped with additional advanced medical technology, those hospitals that are members of a larger system and those that are nonprofit institutions. This is to suggest that there is the need to 
manage these technologies well in order to realize its potential while at the same time not compromising on the other aspects of the organization.

2.2.2 Empirical Studies

Baird et al. (2014) conducted an empirical study on the role corporate governance plays in the adoption of health information technology within integrated delivery systems. They used a cross-sectional, retrospective analyses to analyze the correlation between two corporate governance constructs (centralization of IT decision rights and strategic alignment) and three IT constructs (adoption, standardization and innovation) for clinical and supply chain IT with data from the 2011 Health Information and Management Systems Society Analytics Database on adoption within IDSs $(\mathrm{N}=485)$, by applying multivariate fractional logit, probit, and negative binomial regressions. Baird et al. (2014) observed that multivariate regressions controlling for IDS and market characteristics measures of IT adoption, IT standardization, and innovative IT adoption are significantly associated with centralization of IT decision rights and strategic alignment. They further stated that centralization of IT decision rights is associated with $22 \%$ higher adoption of Bar Coding for Materials Management and $30 \%$ to $35 \%$ fewer IT vendors for Clinical Data Repositories and Materials Management Information Systems.

Wells et al. (2015) researched into the various organizational strategies necessary for the promotion of uptake of personal health records of patient and provider. In their research, they used semi-structured interviews and a web-based survey to sample US health delivery organizations which had implemented PHRs for at least 12 months, where the respondents had lead positions for clinical information systems or high-risk population management. Their result showed that successful PHR implementation represents a social change and operational project catalyzed by a technical solution. However, organizations will likely not achieve the value they want from PHRs unless they target specific population and monitor their uptake.

A review done by West and Bogers (2014) on the contribution and evolution of open innovation literature found that the open innovation had significant impact on research and practice in the past decade. Owing to that, they proposed three emerging trends researchers need: newer and better approaches to measuring open innovation, the role of appropriability in enabling open innovation and the integration of open innovation with established theories of management and economics Hossain et al. (2016).

\subsection{Quantitative analyses of technological innovation management in health care delivery.}

Web of Science which is one of the key databases used for retrieving the articles for this review categorizes its published articles into various disciplines. In the categorization of the articles, one could observe that technological innovation management assumes a multidisciplinary nature but was predominately studied in the areas of health care sciences, which is made up $78.89 \%$, information science library science $(42.22 \%)$ and computer science which was $40.14 \%$ out of the total of 289 articles retrieved. Figure 2 depicts the disciplinary breakdown of the study of technological innovation management in health care delivery based on our search criterion. In terms of actual number of articles published as depicted by Figure 2, health care science, information science library service, computer science, behavioral sciences, business economics, psychology, medical informatics, communication, general internal medicine and mathematical computational biology were $228,122,116,92,91,91,88,70,57$ and 54 respectively. Though our retrieved results gave us about 25 research areas where technological innovation management in health care delivery was studied, the top 10 of those areas were sufficient enough for a good analysis. The surge in the total number of articles published in the health care science services (228) gives an indication of the huge potential technological innovation has on significantly improving quality health care promotion and also creating a more efficient and effective health care delivery systems Lucero (2017) . We also analyze the geographic distribution of the authors and data journal outlets for technological innovation management research. This analysis is informative in terms of interpreting patterns of content, theory and methods used. The number and type of countries involved for instance, provide insights regarding the extent to which the impact of technological innovation management in the healthcare delivery in the public sector may be generalizable and adopted in other countries where research has not picked up yet. Table 1 shows the locations of the authors by their country. The significant number of research articles published were in the USA, topping with a total article of 145 with a percentage of 501.17 out of the total literatures retrieved and analyzed. The USA was followed by England with 33 articles, Canada (19), Australia (16), UK (14), Netherlands (10), Italy (9), Brazil and Spain each had 7 articles followed by Scotland with only 6 articles. 


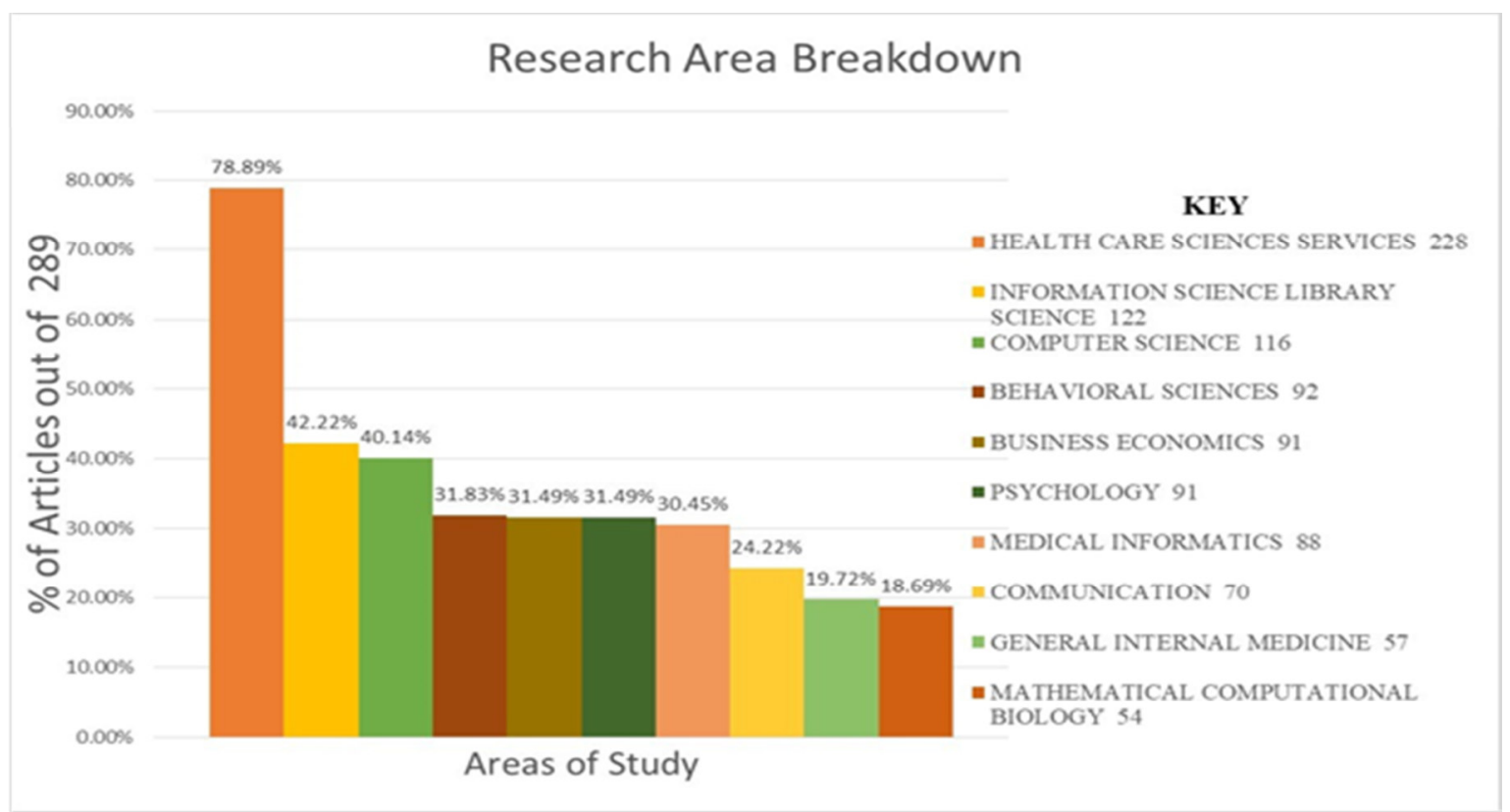

Figure 2: Research area breakdown of the study

Table 1: Location of the authors by country

\begin{tabular}{lccc}
\hline Country & \# of articles & \% of 289 articles & Cumulative \% of 289 articles \\
\hline USA & 145 & 50.17 & 50.17 \\
England & 33 & 11.45 & 61.59 \\
Canada & 19 & 6.57 & 68.17 \\
Australia & 16 & 5.54 & 73.70 \\
United Kingdom & 14 & 4.84 & 78.55 \\
Netherlands & 10 & 3.46 & 82.01 \\
Italy & 9 & 3.11 & 85.12 \\
Brazil & 7 & 2.42 & 87.54 \\
Spain & 7 & 2.42 & 89.97 \\
Scotland & 6 & 2.08 & 92.04 \\
Others (15 countries) & 23 & 7.96 & 100.00 \\
\hline Total & 289 & 100.00 & 100.00 \\
\hline
\end{tabular}

The rest of the countries shared a total of 23 articles with a percentage of only 7.89. Figure 3 shows a graphical representation of the yearly distribution of articles in the area of technological innovation management.

Yearly Distribution

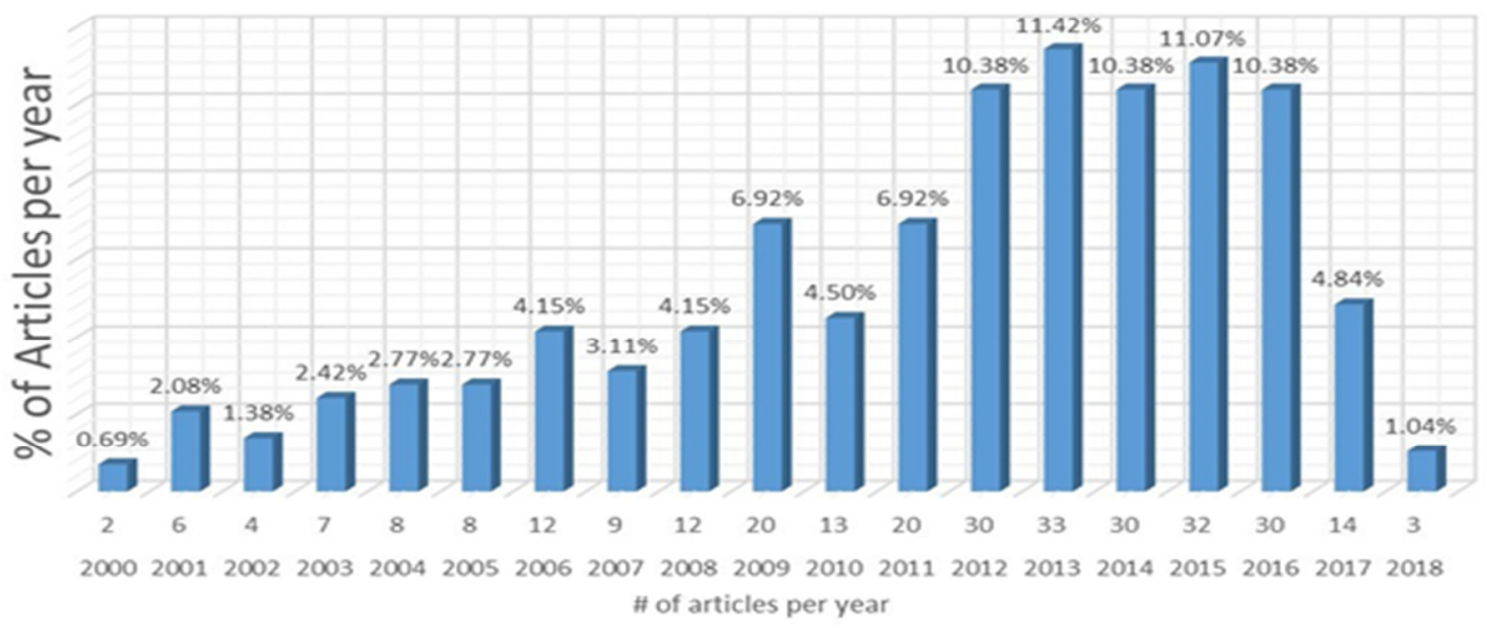

Figure 3: Yearly Distribution of Articles Published (2000-2018)

The yearly distribution indicates a study rise in the number of publications from 2000, which had only 2 
publications at a percentage of 0.69 to until it reached a pick in 2013 (33 publications) indicating $11.42 \%$, then it saw a drop in the following year (2014). Table 2 shows a breakdown of the journals with significantly high (three and above) publications on technological innovation management in health delivery. There are 22 journals which account for total articles of 120 (42.54\%) with the rest of the 58.47 per cent appearing in other journals.

These journals where deliberately not listed in the table, instead they were lumped together under others due to the fact that they do not meet our criteria of having at least 3 publications on technological innovation management in health delivery. International journal of medical informatics topped the list with 14 articles published between the periods of 1990 to 2018, followed by health affairs, health affairs project hope, health care management review with 12,12, and 7 respectively. American Journal of Managed Care, Journal of Advanced Nursing, Nursing Economics, Progress in cardiovascular diseases, Telemedicine Journal and E-Health, and the American journal of managed care occupy the lower portions of the table with each having 3 publications each. The average citations per year of 11 articles on technological innovation management in health delivery as represented in Table 3 was 27.78. The most cited article on technological innovation management in health delivery is Greenhalgh' article "Diffusion of innovations in service organizations: Systematic review and recommendations" Greenhalgh et al. (2004) which was published in Milbank Quarterly journal with an average citations per year of 155.33 and a total citation of 2330. The second highly cited article was authored by Hillestad et al. (2005) titled "Can electronic medical record systems transform health care? Potential health benefits, savings, and costs", with average citations per year of 49.64 with a total citation of 695 in the year 2005. International Journal of Medical Informatics, Health Affairs, and the American Journal of Managed Care were amongst the journals with high contributions in the area of technological innovation management in health delivery.

Table 2: Journals with three and above published articles

\begin{tabular}{|c|c|c|c|}
\hline \multicolumn{2}{|c|}{ Rank Journal Number of } & \multirow{2}{*}{$\frac{\text { Published articles }}{14}$} & \multirow{2}{*}{$\frac{\text { Share of articles }(\%)}{4.84}$} \\
\hline$\overline{1}$ & International Journal of Medical Informatics & & \\
\hline 2 & Health Affairs & 12 & 4.15 \\
\hline 3 & Health Affairs Project Hope & 12 & 4.15 \\
\hline 4 & Health Care Management Review & 7 & 2.42 \\
\hline 5 & Telemedicine Journal and E-Health & 7 & 2.42 \\
\hline 6 & BMC Medical Informatics and Decision Making & 6 & 2.08 \\
\hline 7 & Journal of Medical Systems & 6 & 2.08 \\
\hline 8 & Studies in Health Technology and Informatics & 6 & 2.08 \\
\hline 9 & BMC Health Services Research & 4 & 1.38 \\
\hline 10 & Journal of General Internal Medicine & 4 & 1.38 \\
\hline 11 & Journal of Medical Internet Research & 4 & 1.38 \\
\hline 12 & Journal of the American Medical Informatics Association & 4 & 1.38 \\
\hline 13 & Population Health Management & 4 & 1.38 \\
\hline 14 & Technological Forecasting and Social Change & 4 & 1.38 \\
\hline 15 & Telemedicine and E Health & 4 & 1.38 \\
\hline 16 & American Journal of Managed Care & 3 & 1.04 \\
\hline 17 & Journal of Advanced Nursing & 3 & 1.04 \\
\hline 18 & Nursing Economics & 3 & 1.04 \\
\hline 19 & Progress in Cardiovascular Diseases & 3 & 1.04 \\
\hline 20 & Telemedicine Journal and E Health & 3 & 1.04 \\
\hline 21 & The American Journal of Managed Care & 3 & 1.04 \\
\hline 22 & Others & 173 & 58.48 \\
\hline
\end{tabular}

\section{Results and Discussion}

The essence of this study is to systematical review literature on the impact of technological innovation management in health care delivery. The content analysis showed contributions of major conceptual, empirical, evidential and review articles. Based on the literature reviewed, we created a framework for technological innovation management research. The framework sought to shed light on the progress of existing research on technological innovation management and suggested some approaches for future research as shown in Figure 4. The study relied on keyword and topic analysis that are closely related to technological innovation and technological innovation management.

We observed that there is the need to extend research into some essential and emerging areas such as intellectual property (IP) issues in the implementation and adoption of technological innovations and TIM in the health care sector, implications of ethical issues of technological innovation management on health care service delivery especially in the public sector, public health context of technological innovation management (TIM), measuring technological innovation (TI) in health care delivery, technological innovation management impact on 
health insurance. Other important areas that researchers also need to be looking at in terms of new studies is the implication of technological innovation management on service delivery for aged care, impact of technological innovation management on performance and efficiency in developing countries such as Ghana, China etc.

We observed that while not so much of research has been done specifically in determining the impact technological innovation management has on the delivery of health care services in the public health sector, some expansive study in other field of study has taken place. Open innovation which was part of our keywords was dominantly researched mainly in the disciplines of management, business and operation research but not an integration of traditional management with management of technology innovation. Many researchers and scholars have emphasized an integrating of technological innovation with some established theories of management and economics and other disciplines Hossain et al. (2016). We observed that approaches for measuring technological innovation management are either still at a preliminary stage or non-existent. Hence, health care delivery institutions have no established models and frameworks to measure the impact technological innovation management has on the health care service delivery in the public sector.

Some of the studies have often discussed the benefits of technological innovation, and few have also concentrated on the impact of policy makers and their policies on the adoption of such disruptive technological innovation such as telemedicine, but not on the impact of management of such technological innovations on service delivery or the limitations of those technological services.

From our review, we observed that the conceptualization and knowledge of technological innovation management is limited. Hence, there is the need for more knowledge and research in this area to make the adoption of technological innovation easier for managers and policy makers. It is prudent for researchers to avert their minds to longitudinal research as an important approach for their future research. There is the need for the incorporation of more semi-structured interviews, systematic literature reviews, web-based surveys, empirical studies and in-depth interviews approaches for conducting future research into technological innovation management. In order for future researches to be generalizable, there is also the need for these approaches to target studies at regional, national, and international levels. There is also the need for researchers to adopt the approach of using case studies and large- scale primary data for their future.

We observed that the representation of scholars who attempted to research into technological innovation management, accounts for a small number of institutes in the USA and Europe; thus, there is a need for more diversity in the nationalities of the authors. We propose that future studies should focus more on emerging countries, such as Ghana, China, Rwanda and other developing nations.

\section{Conclusion}

Though there has been some research into the area of innovation, open innovation and the application of technological innovation in the area of health care delivery, little study has been done in assessing the impact management of such technological innovation on the delivery of public health care services to citizens. Thus, there is the need to extend research into this important area, coupled with some essential and emerging areas such as intellectual property (IP) issues in the implementation and adoption of technological innovations and TIM in the health care sector. After a thorough analysis of the contents of the literature reviewed, we created a framework for technological innovation management research. This framework was created to shed light on the progress of existing research on technological innovation management, and suggests some approaches for future research. Scholars could explore additional types of publications such as books, conference articles, magazine and newspaper articles, policy papers, working papers and professional and expert reports in their future studies.

\section{Conflict of interest}

The authors declare that there are no financial support or relationship that may pose conflicts of interest to this review.

\section{References}

Adler-Milstein, J., Kvedar, J., and Bates, D. W. (2014). Telehealth among us hospitals: Several factors, including state reimbursement and licensure policies, influence adoption. Health Affairs, 33(2):207-215.

Alexy, O. and George, G. (2013). Category divergence, straddling, and currency: Open innovation and the legitimation of illegitimate categories. Journal of Management Studies, 50:173-203.

Baird, A., Furukawa, M. F., Rahman, B., and Schneller, E. S. (2014). Corporate governance and the adoption of health information technology within integrated delivery systems. Health Care Management Review, 39(3):234-244.

Benner, M. J. and Tushman, M. L. (2003). Exploitation, exploration, and process management: The productivity dilemma revisited. Academy of management review, 28:238-256.

Charter, M. and Clark, T. (2007). Sustainable innovation: Key conclusions from sustainable innovation conferences 2003-2006 organised by the centre for sustainable design. 
Chesbrough, H. (2010). Business model innovation: Opportunities and barriers. Long Range Planning, 43:354363.

Chesbrough, H. W. (2003). The era of open innovation. MIT Sloan Management Review, 44:35-41.

Christiansen, J. K., Gasparin, M., and Varnes, C. J. (2013). Improving design with open innovation: A flexible management technology. Research-Technology Management, 56:36-44.

Clegg, D. and Barker, R. (1994). Case method fast-track: a RAD approach.

Curristine, T. (2005a). Government performance. OECD Journal on Budgeting, 5:127-151. b.

Curristine, T. (2005b). Government performance: Lessons and challenges. OECD Journal on Budgeting. a. da Mota Pedrosa, A., Välling, M., and Boyd, B. (2013). Knowledge related activities in open innovation: managers' characteristics and practices. International Journal of Technology Management 12, 61:254-273.

DIISR (2011). "Working towards a measurement framework for public sector innovation in australia,".

Duin, P. V. D., Ortt, R., and Kok, M. (2007). The cyclic innovation model: A new challenge for a regional approach to innovation systems? European Planning Studies, 15:195-215.

Evangelista, R. and Vezzani, A. (2010). The economic impact of technological and organizational innovations. A firm-level analysis. Research Policy, 39:1253-1263.

Friedman, L. G. (2002). Go-to-market strategy: advanced techniques and tools for selling more products, to more customers, more profitably.

Giannopoulou, E., Yström, A., Ollila, S., Fredberg, T., and Elmquist, M. (2010). Implications of openness: A study into (all) the growing literature on open innovation. Journal of technology management \& innovation, 5:162-180.

Gold, M. (2013). Employing health information technology in the real world to transform delivery. American Journal of Managed Care, 19:377-381.

Golder, P. N. and Tellis, G. J. (1993). Pioneer advantage: Marketing logic or marketing legend? Journal of marketing Research, pages 158-170.

Greenhalgh, T., Robert, G., Macfarlane, F., Bate, P., and Kyriakidou, O. (2004). Diffusion of innovations in service organizations: systematic review and recommendations. The Milbank Quarterly, 82:581-629.

Gyampoh-Vidogah, R., Moreton, R., and Sallah, D. (2009). Reducing health cost: Health informatics and knowledge management as a business and communication tool.

Haag, S., Cummings, M., and Dawkins, J. (1998). Management information systems for the information age. McGraw-Hill.

Harzing, A. W. K. and Wal, R. (2008). Google scholar as a new source for citation analysis. Ethics in science and environmental politics, 8(1):61-73.

Hillestad, R., Bigelow, J., Bower, A., Girosi, F., Meili, R., Scoville, R., and Taylor, R. (2005). Can electronic medical record systems transform health care? Potential health benefits, savings, and costs. Health Affairs, 24(5):1103-1117.

Hossain, M., Islam, K. Z., Sayeed, M. A., and Kauranen, I. (2016). A comprehensive review of open innovation literature. Journal of Science \& Technology Policy Management, 7(1):2-25.

Jennerich, B. (1990). Joint application design-business requirements analysis for successful reengineering.

Bluebird Enterprises Inc.

Kurhekar, M. and Ghoshal, J. (2010). Technological innovations in healthcare industry.

Langer, M., Torresani, M., Sini, E., Fiore, L., Facchini, R., Ficagna, M., and Minelli, M. (2013). Improving patient care process supporting both medical and non-medical activities through ICTS.

Li, J., Westbrook, J., Callen, J., and Georgiou, A. (2012). The role of ict in supporting disruptive innovation: a multi-site qualitative study of nurse practitioners in emergency departments. Bmc Medical Informatics and Decision Making, 12.

Little, A. D. (2005). How leading companies are using sustainability-driven innovation to win tomorrow's customers. Innovation High Ground Report.

Long, T. B., Blok, V., and Coninx, I. (2016). Barriers to the adoption and diffusion of technological innovations for climate-smart agriculture in Europe: evidence from the Netherlands, France, Switzerland and Italy. Journal of Cleaner Production, 112:9-21.

Lucero, R. J. (2017). Improving health promotion and delivery systems through information technology.

Nursing Economics, 35(3):145-146.

Maghsoudi, S., Duffield, C., and Wilson, D. (2015). Innovation evaluation: past and current models and a framework for infrastructure projects. International Journal of Innovation Science, 7:281-297.

Moher, D. (2009). Preferred reporting items for systematic reviews and meta-analyses: the prisma statement.

PLoS medicine, 6(7):1000097.

Rantala, T., Ukko, J., Saunila, M., and Havukainen, J. (2018). The effect of sustainability in the adoption of technological, service, and business model innovations. Journal of Cleaner Production, 172:46-55.

Sapprasert, K. and yvarde Clausen, T. H. (2012). Organizational innovation and its effects. Industrial and 
Corporate Change, 21:1283-1305.

Tranfield, D., Denyer, D., and Smart, P. (2003). Towards a methodology for developing evidence-informed management knowledge by means of systematic review. British journal of management, 14:207-222. Null. Ulaga, W. and Eggert, A. (2006). Value-based differentiation in business relationships: Gaining and sustaining key supplier status. Journal of marketing, 70:119-136.

Ward, J. and Elvin, R. (1999). A new framework for managing it-enabled business change. Information Systems Journal, 9(3):197-221.

Wells, S., Rozenblum, R., Park, A., Dunn, M., and Bates, D. W. (2015). Organizational strategies for promoting patient and provider uptake of personal health records. Journal of the American Medical Informatics Association, 22(1):213-222.

West, J. and Bogers, M. (2014). Leveraging external sources of innovation: a review of research on open innovation. Journal of Product Innovation Management, 31:814-831.

Zahra, S. A., Nash, S., and Bickford, D. J. (1995). Transforming technological pioneering into competitive advantage. The Academy of Management Executive, 9:17-31.

Zeithaml, V. A. (1988). Consumer perceptions of price, quality, and value: a means-end model and synthesis of evidence. The Journal of marketing, pages 2-22.

Zhou, K. Z., Yim, C. K., and Tse, D. K. (2005). The effects of strategic orientations on technology-and marketbased breakthrough innovations. Journal of marketing, 69:42-60.

Zoltners, A., Sinha, P., and Lorimer, S. (2004). Sales force design for strategic advantage. 


\section{Appendices}

Table 1 Papers with average citations per year of 27.78

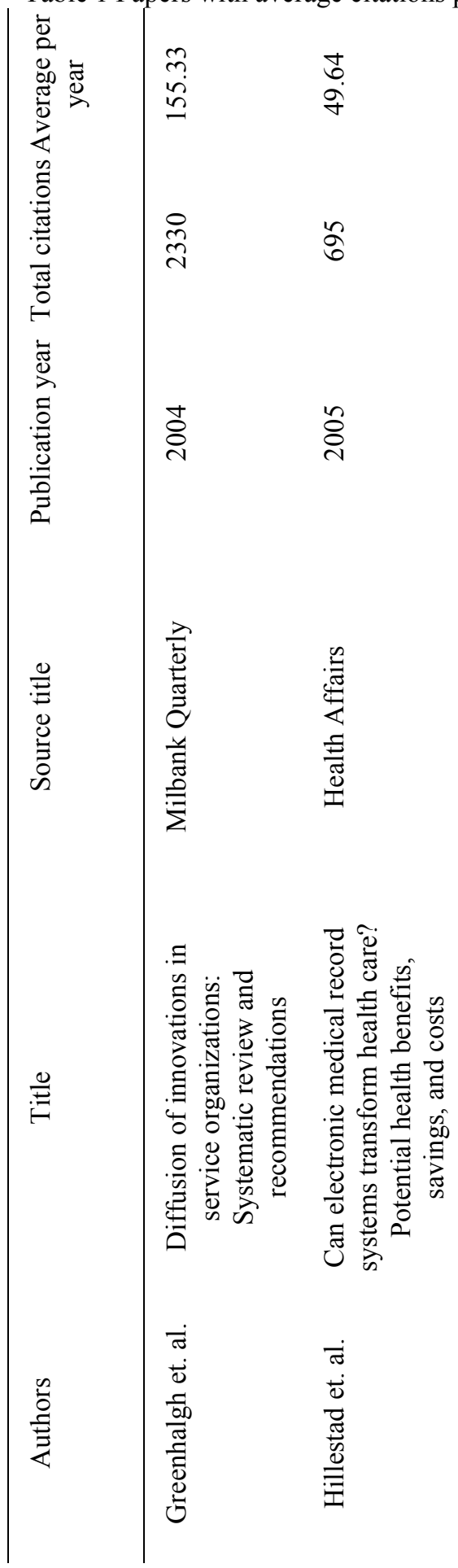

$\underset{\check{\sigma}}{\check{\Xi}}$

$\frac{1}{n}$

$\overline{8}$

苞

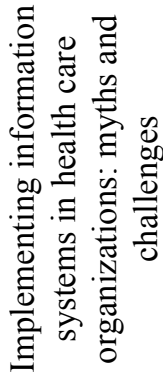

$\sum$
oi
को $\stackrel{8}{\text { ă }}$

$\stackrel{\Re}{\mathfrak{0}}$

$\stackrel{n}{\infty}$

$\overline{6}$

ঠ্ণ

ปั

3
0
0
0
0
0
0
0
0
0
0
0
0
0
0
0

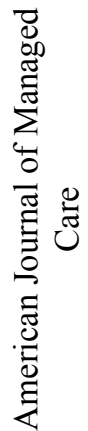

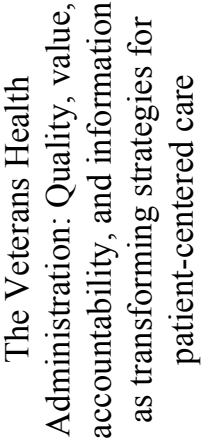

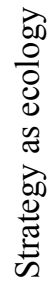

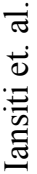


Table 3 continued.

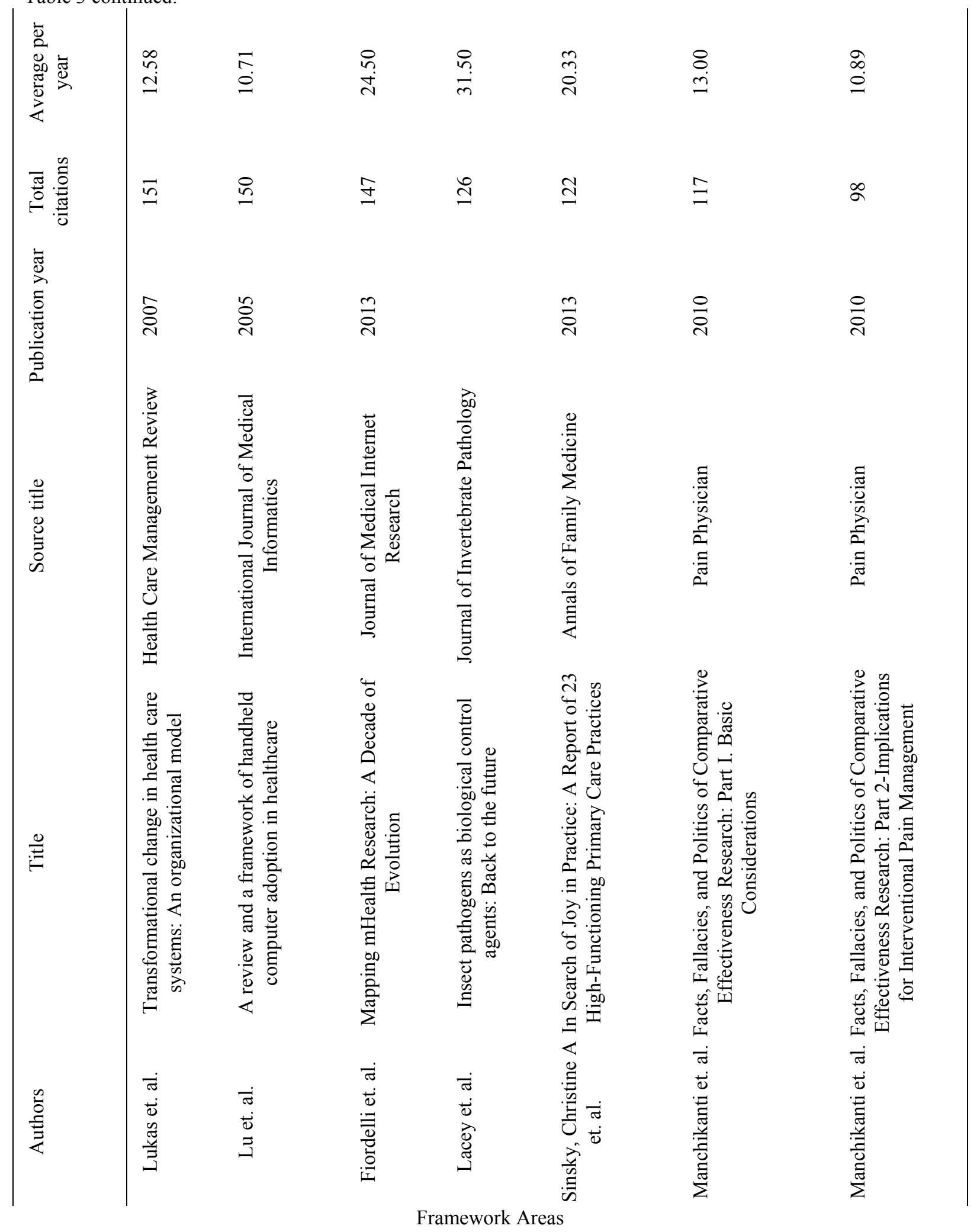




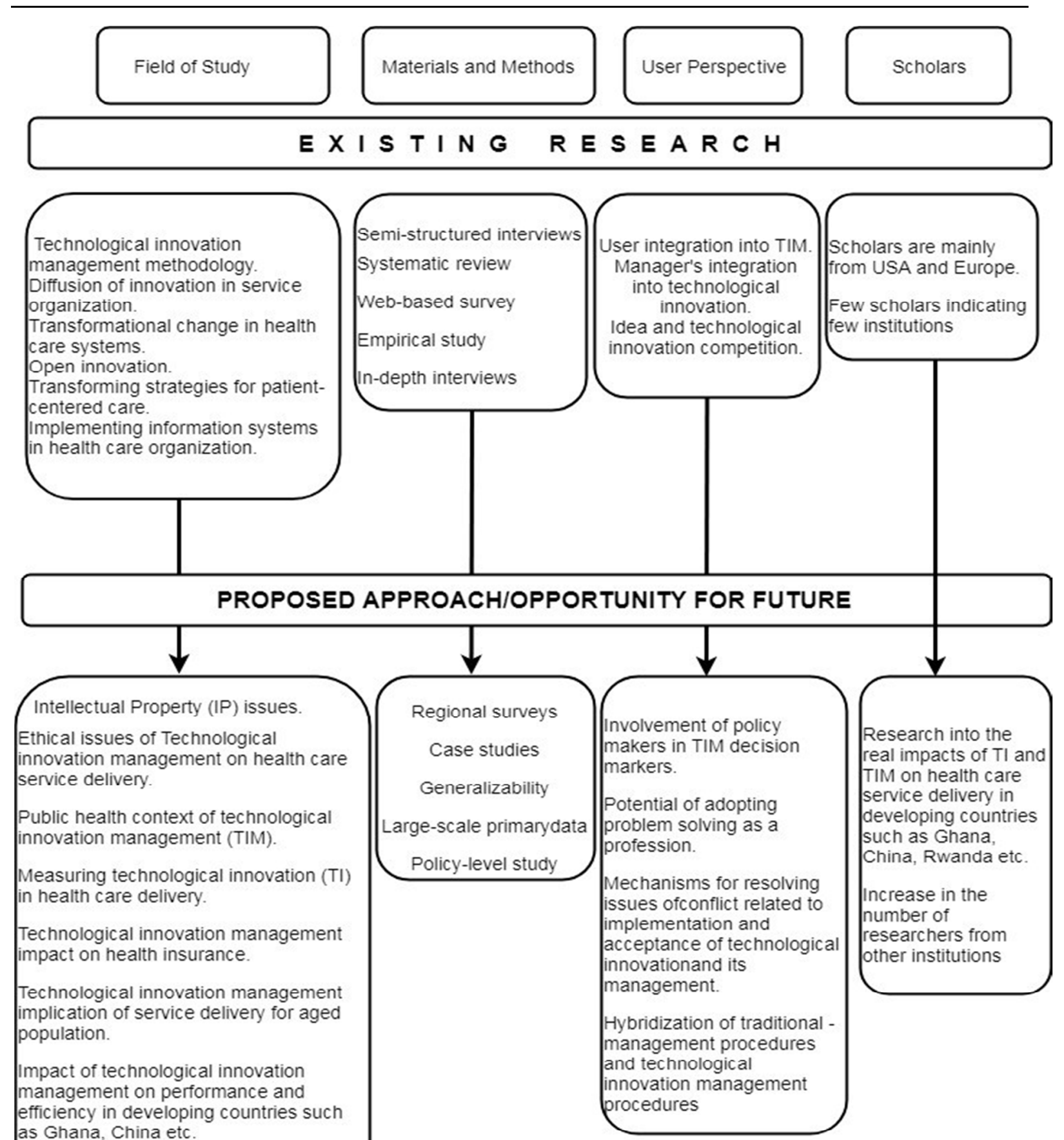

Figure 4: Existing, emerging and proposed approach/opportunity for future research 